\title{
Social origins and the decision to leave university during the Great recession: the role of the field of study
}

\author{
Loris Vergolini ${ }^{1}$ and Eleonora Vlach ${ }^{2}$
}

\begin{abstract}
The recent economic downturn has had profound influences on contemporary European societies. This paper analyzes how the Great Recession affected the drop-out rate among university students in Italy, and whether their chosen field of study moderated its effect. To examine the potential long-term effects of this economic downturn on social inequality, we also explore whether students from less-advantaged families who enrolled in prestigious fields were those pushed out from university in disproportionally high numbers. We investigate the interacting influence of the economic crisis, social inequalities and field of study on drop-out rate using data from the Istat "Survey on the educational and occupational paths of high school graduates" in two cohorts of university students (one who attended university prior to and one during the Great Recession). Results obtained from propensity score matching show that the economic crisis had a negative effect on university participation, which was however less strong for Medicine students. Students from lower socio-economic backgrounds in the most remunerative fields of study (those leading to liberal professions), tended to leave university more often than their well-off peers.
\end{abstract}

Keywords: Great Recession, Drop-out, Higher education, Field of study

\footnotetext{
Loris Vergolini

vergolini@fbk.eu

1 FBK-IRVAPP, Via Santa Croce 77, 38122 Trento (IT).

2 Goethe University Frankfurt, Theodor-W.-Adorno-Platz, 6 - 60629 Frankfurt am Main (DE).
}

\begin{abstract}
Acknowledgments
The authors would like to thank Markus Gangl, Cristina Iannelli, Nicole Tieben and Moris Triventi for their useful suggestions on a previous version of this paper. We received many helpful comments on earlier versions of this paper from participants at the 2017 ISA RC28 Spring Meeting (University of Cologne, DE), at the $26^{\text {th }}$ Annual Workshop of the European Research Network on Transitions in Youth (University of Mannheim, DE) and at the 2019 ISA RC28 Spring Meeting (University of Frankfurt, DE).
\end{abstract}




\section{Introduction}

The recession that followed the financial crisis of 2007-08, with a downward leap of approximately $5 \%$ of OECD countries' economic prosperity, has had profound influences on contemporary European societies (Grusky et al. 2011). Evidence of this Great Recession's short- and medium-term effects includes reduced employment chances for individuals, deterioration of households' economic conditions and an increased aggregate level of poverty and inequality in both the USA (Reinhart and Rogoff 2009; Grusky et al. 2011) and Europe (Jenkins et.al. 2013). In this paper our attention is focused on the potential long-term effects of the crisis on social inequality. The deterioration of the economic situation faced by adults likely had a negative impact on their offspring as well, both in psychological (increased tension within the family) and material terms (ability to pay for goods and services). Through this indirect channel, the crisis might have influenced offspring's chances of pursuing prestigious and expensive educational choices and thus their future occupational status. As educational degrees are a strong predictor of the future occupational position, in this paper we suggest that analyzing the effects of the Great Recession on dropping out of university according to social background reveals the potential long-term effects of the crisis on social inequality. While the influence of the Great Recession on both university enrolment (Barr and Turner 2013) and drop-out risk (Ghignoni 2017) already attracted scholarly attention, little is known on the role of the field of study as a potential mediator of the association between social origins and withdrawing from university. In other words, the question as to whether certain fields of study are better than others in protecting students from dropping out during economic downturns is still unanswered. Hence, we aim at contributing to the debate by analyzing how the Great Recession affected social origins inequality in the decision to leave university according to the field of study.

Policy makers in contemporary Western societies often address higher education as a central arena for investments devoted at increasing national economic performance and reducing social inequality. On the one side, longer permanence in the educational system allows young people to acquire higher levels of human capital and skills that, at the aggregate level, positively correlate with higher levels of socioeconomic development (Hanushek and Woessmann 2008; 2012). On the other side, educational credentials are usually considered by students and their families as means of protection against being employed in lower-paying jobs (Breen and Jonsson 2005; Hout and Di Prete 2006). Thus, it is unsurprising that withdrawing from university is seen as a waste of public and private resources (Aina 2013) and as a threat to policy makers' efforts to decrease inequality in educational opportunities.

We believe that Italy in particular represents an interesting case in this regard. With 4 out of every 10 students leaving university without a degree, Italy has one of the highest drop-out rates in Europe 
(OECD 2018). Among European countries, Italy also has the lowest rate of tertiary completion after a drop-out episode: only $6.1 \%$ of Italians eventually gain a degree after a drop-out, compared to $37.7 \%$ in Germany and 58.2\% in Sweden (Schnepf 2017). In other words, leaving university constitutes a much more definitive choice in Italy than in any other European country. Because of both the dimension of the phenomenon of withdrawing and its significance for an individual's educational career in this country, focusing on Italy can help to detect potential effects of the economic crisis potentially present yet less visible in other European countries, due to the lower numbers involved. In addition, although recently more and more scholars have addressed the determinants of university enrollment in Italy, the phenomenon of university disenrollment is still substantially understudied ${ }^{1}$, despite its high social relevance in the country.

In the next section we provide a detailed description of the Italian context for what concerns both the education system and economic situation in the years of the Great Recession. Section 3 illustrates the theoretical background, the previous literature, and the research hypotheses. Section 4 clarifies the data, variables and methods, while section 5 presents the results of our analyses. Finally, section 6 summarizes and discusses our main findings.

\section{The context}

\subsection{The Italian education system}

Education in Italy is compulsory for children aged 6 to 16 years and it is organized in four stages: primary school, lower secondary school, upper secondary school and tertiary education. Tracking appears at upper secondary school (from $9^{\text {th }}$ grade onwards) where three tracks are available: academic (liceo), technical (istituto tecnico) and vocational track (istituto professionale). Each track lasts five years and ends with an examination of competencies known as Esame di Maturità. Every student who passes this exam may enroll at university, regardless of which track he or she completes. ${ }^{2}$

The implementation of the Bologna Process in 2001 deeply changed the Italian tertiary education system. The previous system was based on a single tier that lasted between 4 and 6 years, depending on the chosen field of study. It was particularly selective and characterized by a high workload. The state of affairs changed dramatically after the introduction of the Bologna process, announced in 1999 and fully implemented already in 2001. Compared to other European countries, Italy was an outlier with respect to the time of the implementation of the reform: the policy maker opted for an immediate

\footnotetext{
${ }^{1}$ One reason for this is the limited availability of pertinent survey data. However, since 2010, the Italian Ministry of Education has collected administrative information about all students and their educational careers in Italy (in the socalled Anagrafe Nazionale degli studenti - National Register of Students). This information is not yet linked to the individual characteristics needed to analyze inequality in educational opportunities.

${ }^{2}$ Some vocational schools, managed at local level, offer three years qualifications, which do not grant access to university.
} 
full implementation, being the reform intended as a tool to solve urgent problems of Italian tertiary education: low enrollment rates and frequent drop-outs. Higher education in Italy since 2001 is organized according to a sequential system, the so-called " $3+2$ ", which comprises a 3-year bachelor's degree, resulting in the laurea, plus a 2-year master's degree leading to the laurea magistrale. The latter is a prerequisite for doctoral programs. The differences in terms of prestige and reputation between Italian universities are practically negligible, especially when compared to the higher education systems of France, the United Kingdom or the United States, which are characterized by the presence of elite institutions. As a result, the choice of the field of study in Italy is a particularly relevant decision, to which prestige and future remuneration is related.

\subsection{The economic conjuncture}

The Great Recession constitutes by far the worst economic downturn in Italy in the last 70 years (Brandolini et.al. 2011). Figure 1 shows descriptive statistics on the economic situation of the country between 2000 and 2016. GDP data (Figure 1, panel a) signal a steep decline in 2009, accompanied by a long-lasting downward trend between 2009 and 2015. Because the contraction of the Italian employment rate during the Great Recession was most affected by the non-renewal of fixed-term contracts rather than layoffs (D'Amuri 2011), data on both the general and youth unemployment ${ }^{3}$ rates (Figure 1, panels b and c) provide a better picture of when students and their families started to experience conspicuous losses of economic resources. It has been in 2008, but even more from 2009, that the youth employment rate boomed, reaching more than $17 \%$. Our results are in line with that of Brandolini et.al. (2011), who show how the average monthly equivalent disposable income in 2008 remained roughly equal to 2007, and began shrinking starting in 2009. As a result, the incidence of relative poverty in 2010 was already 1.8 times greater than that of 2007.

The increase in the general unemployment rate resulted in worsened economic conditions within the families, which made university participation of youth less affordable. At the same time, the growing rate of youth unemployment mirrors declining chances for youths to find a job. These two phenomena portray a situation in which direct costs increase, while opportunity costs decrease. It should be noted that, contrary to the countercyclical characteristics of enrollment rates at American universities (Christian, 2007; Barr, 2013), every economic crisis since the 1970's has been accompanied by a negative effect on the transition rates from upper secondary school to university in Italy (Schizzerotto et.al., 2018).

\footnotetext{
${ }^{3}$ More precisely, we report the unemployment rate for people aged 18-29 with an upper secondary school qualification. For the sake of simplicity, this indicator is referred to as the youth unemployment rate.
} 
Figure 1. Descriptive statistics.

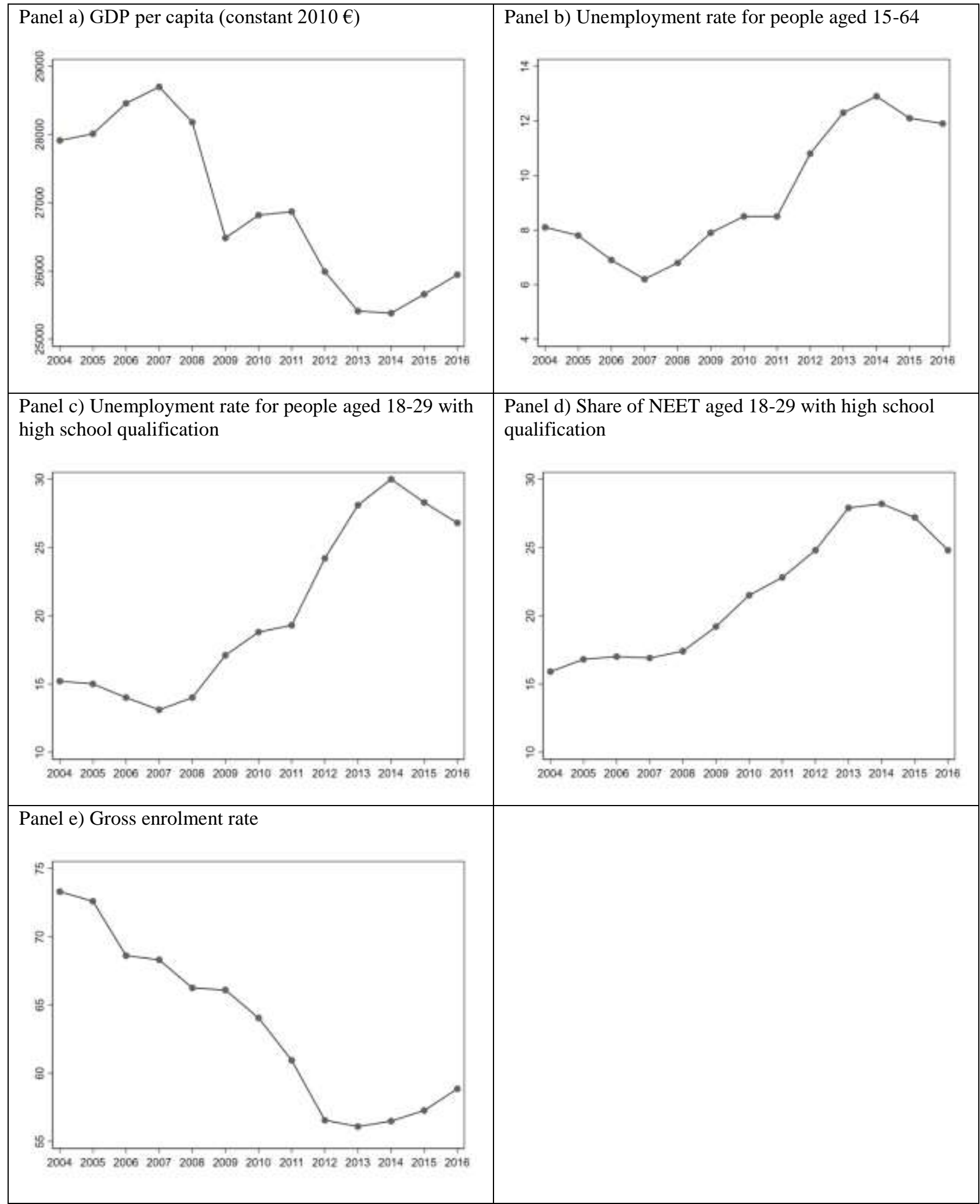

Note: The gross enrollment rate is the ratio between all individuals enrolling at university for the first time in the academic year $\mathrm{t}$ - regardless of the year in which they obtained a high-school qualification - and the number of pupils who passed the final high school examinations in the school year $\mathrm{t}-1$.

Source: Data for panels $a, b, c, d$ was supplied by the Italian Statistical Office (Istat) through the I.Stat data warehouse, while data for panel $e$ was provided by the Italian Statistical Yearbook for the number of students enrolled in university for the first time and data supplied by the Italian Ministry of Education (Anagrafe nazionale degli alunni) for the number of high school graduates. 
This is also shown by macro data on gross enrollment rates (Figure 1, panel e). Note that the Great Recession accelerated the previously decreasing trend in enrollment rates. It has to be also stressed that the proportion of NEET (not in education, employment or training) increased sharply in the aftermath of the economic crisis (Figure 1, panel d).

\section{Theoretical framework and hypotheses}

In this section we present the theoretical framework that guides our empirical analysis. We start the discussion with arguments on the relationship between social origins and university participation and successively decline them in a context influenced by the Great Recession.

\subsection{Social background and university participation}

Following a rational action theory (RAT) approach (Breen and Goldthorpe 1997), educational choices - in our case university persistence (i.e. not dropping-out) are influenced by three main factors. First, the costs involved in enrolling/remaining in education: which can be direct (tuition fees, expenses for learning materials, etc.) or indirect costs (renounced earnings). Second, the likelihood of success at the successive stage in case of continuation (i.e. the probability of receiving a degree). Third, the perceived benefit of each available alternative (in our case: remaining at university vs dropping out). While both the likelihood of success and the perceived benefit positively influence university participation, the direct and indirect costs exert a negative influence. This argument can be summarized by the following formula:

$$
U=(P \cdot B)-\left(C_{d}+C_{o}\right)
$$

where $U$ is the utility of university persistence, $P$ the probability of success, $B$ the expected benefit, and $C_{d}$ and $C_{o}$ are respectively the direct and indirect (or opportunity) costs.

A student's socioeconomic background can influence university persistence through each of these factors. Children from more educated and well-off parents not only can rely on the higher economic resources of their parents to undertake expensive educational choices, but also the higher parental cultural capital will be better suited to sustain their competence development. In this way a virtuous circle with beneficial effects on the likelihood of educational success is triggered. In addition, because individuals aim to maintain at least the same living standards they experienced while growing up, the benefit attached to educational alternatives will be influenced by the family of origin's socioeconomic status. More precisely, students from more advantaged families will attach a higher utility to prestigious educational degrees, the only likely to protect them from the risk of downward social mobility. Children from less advantaged families could instead achieve the same result through less demanding educational choices. 
The predictions derived from RAT received recurrent empirical support in the international literature (see e.g. Becker and Hecken 2009; Argentin and Triventi 2011 and Stocké 2019 for a review of the empirical studies supporting RAT). Studies on university drop-out are relatively less common, but since drop-out is the opposite of educational participation the above considerations are equally applicable to the study of the decision to leave university. Similar to university enrollment, the decision to withdraw after initial enrollment is heterogeneously distributed across socioeconomic backgrounds: less advantaged students are more likely than their peers with highly educated parents to prematurely leave university.

Previous studies have revealed a social gradient in dropping-out in several different countries, such as in the US (Stratton et al. 2008); UK (Smith and Naylor 2001; Crawford 2014); Scotland (Christie et al. 2004), Spain (Lassibille and Navarro Gomez 2008); France (Gury 2011) and Italy (Di Pietro 2004; Di Pietro and Cutillo 2008; Triventi and Trivellato 2009; Aina 2013; Cingano and Cipollone 2017). However, analyses of the decision to leave university rarely focused on the horizontal dimension of education (the field of study). Yet, as pointed out by Lucas (2001), the consideration the vertical dimension of education is not enough to fully understand how social inequalities are reproduced in contemporary Western societies. Indeed, students from the most advantaged socioeconomic backgrounds are prone to exploit both the vertical and horizontal dimensions of education, when the former does not guarantee protection from the risk of downward social mobility. The perceived benefit of a degree, in fact, depends not only on the mechanism of status maintenance addressed above, but also on the (expected) specific economic return of the degree on the labor market, which increasingly depends on the field of study (Reimer et al. 2008; Triventi 2013, Ballarino and Bratti 2009, Vergolini and Vlach 2017).

The theoretical framework addressed above is also coherent with Tinto's Student Integration Model (1975; 2006), one of the most comprehensive theoretical models explaining drop-out behavior. Tinto's model argues that the decision to leave university is the final output of a process influenced by several factors at both the individual and the institutional level. At the individual level, students' pre-entry attributes (i.e., social origins, prior abilities and previous educational choices) as well as motivations, intentions and aspirations (in Tinto's words: goals and commitments) are critical. Key factors at the institutional level include instead students' interactions with their peers and the university body, which affect students' sense of academic and social integration. Due to data availability, in the current paper our attention is focused on the role of students' individual features only. 


\subsection{The Great Recession and the decision to leave university}

The Great Recession, by negatively affecting families' economic resources and individuals' opportunities on the labor market, is likely to have conspicuously influenced the evaluations of the costs and benefits of university persistence. In this section we adapt the theoretical model depicted in the previous section to account for individuals' rational responses to changes resulting from an exogenous shock like an economic crisis. Table 1 summarizes the possible effects addressed below. First, we expect that the Great Recession increased the relative weight of direct costs $\left(C_{d}\right)$ in the equation for predicting university persistence. As seen in the previous section, the economic crisis greatly diminished households' disposable income, making tertiary education less affordable for students and their families, regardless of the specific field of study. On the basis of this reasoning, we formulate our first hypothesis:

Hla: Increasing direct costs result in an increased drop-out rate (regardless of the field of study).

Table 1. The effect of costs, likelihood of success and perceived benefit on university participation and persistence in periods of economic expansions and recessions.

\begin{tabular}{lcll}
\hline Factor & $\begin{array}{c}\text { Economic } \\
\text { expansion }\end{array}$ & $\begin{array}{c}\text { Great } \\
\text { Recession }\end{array}$ & Arguments \\
\hline Direct costs & - & -- & $\begin{array}{l}\text { Worsened household's economic } \\
\text { condition }\end{array}$ \\
Opportunity costs & - & + & $\begin{array}{l}\text { Increase in youth unemployment } \rightarrow \\
\text { warehouse effect }\end{array}$ \\
Likelihood of success & + & + & No changes \\
Economic returns & + & $+/-$ & $\begin{array}{l}\text { Different field of studies could be } \\
\text { differently affected by the crisis }\end{array}$
\end{tabular}

As shown by the utility function above, however, direct costs constitute just a portion of the total costs of tertiary education, another important part is foregone earnings (i.e., opportunity or indirect costs). During periods of economic growth, indirect costs could keep some students away from university due to good opportunities on the labor market that high school graduates may enjoy.

This changes during economic recessions, when vast youth unemployment greatly reduce indirect costs. In this scenario the youth unemployment rate exerts an important positive effect on the probability that an individual remains in education (for simplicity, shown in Table 1 as a plus for opportunity costs), resulting in a lower drop-out rate. This argument begets an alternative hypothesis: 
H1b: Reducing opportunity costs result in a decreased drop-out rate (regardless of the field of study).

Previous studies on the Italian case in this regard do not seem to converge. Adamopoulou and Tanzi (2017) highlight reduced social inequality in university participation in the aftermath of the Great Recession, with a decrease in the drop-out risk in addition to an increased likelihood of on-time graduation for highly motivated students. The evidences reported by Ghignoni (2017) suggest that the influence of social origins on the decision to leave university has instead strengthened with respect to the pre-crisis period. Given the great impact of the Great Recession in Italy, we believe that the scenario depicted by Hla could be the most reliable, as university persistence in times of economic crisis may have become too costly and those more stricken by the crisis tended to become NEET (see Figure 1, panel d).

The portrayed situation becomes substantially more complex when we acknowledge that the population of students, rather than being homogeneous, is divided into really diverse fields of study. The choice of a field plays a significant role for both tertiary education experiences and future prospects on the labor market. Fields are each associated with different levels of direct costs, where the most remunerative ones (e.g., those leading to liberal professions: medicine, law, engineering) can be very expensive. Economic resources are needed to travel to and live in the few cities that host such departments in Italy, buy high-priced books and other expensive study materials. Remunerative fields of study may also require more time in order to prepare exams, and are thus potentially less compatible with part-time work.

Focusing on the role of direct costs, which we expect is the principal underlying mechanism, one could expect that their increase especially affected students enrolled in the most expensive fields, leading to a greater increase in the drop-out rate from those fields in particular.

H2a: The increase in the drop-out affects remunerative fields of study the most.

At the same time, it has to be noticed that the most prestigious fields also provide better opportunities on the labor market (in terms of both employability and future earnings). Students and their families may then perceive them as worthy of a greater self-denial. In our theoretical argumentation, the question arises: are the greater benefits associated with the most remunerative degrees high enough to better protect students from the negative influences of the Great Recession? If yes, we expect to find that:

H2b: The increase in the drop-out affects the most prestigious fields of study the least. 
Going back to the utility function above, to consider the opposing scenarios of $H 2 a$ and $H 2 b$ means asking ourselves which factor, between the expected benefit $(B)$ and the direct costs $\left(C_{d}\right)$, matters the most. $^{4}$

Eventually, in order to investigate the potential long-term effects of the Great Recession on social inequality, we analyze whether the crisis affected the choice to drop-out differently by field of study and social origin. More precisely, we aim at understanding whether were especially students from underprivileged families that despite fewer socio-economic resources were pursuing the most prestigious educational choices those that suffered the most from the Great Recession, as opposed to their more affluent peers pursuing a path of social reproduction. We expect that the increase in the costs of attending higher education affected more severely the small group of students on a path of upward social mobility attending already very expensive fields of study. Thus, our final hypothesis is:

\section{H3: Students from less wealthy families enrolled in the most remunerative fields of study} experience the highest drop-out rate.

\section{Data, variables and method}

This section is divided into two parts. The first part provides detailed information about the data and variables considered in this study. The second part illustrates the method for estimating the effect of the Great Recession on withdrawal (propensity score matching) and introduces the logic behind a set of robustness checks performed later.

\subsection{Data and variables}

We employ data from the two latest available waves of the "Survey on the educational and occupational paths of high school graduates" (SPHG henceforth). The SPHG is a repeated crosssectional study of representative samples of Italian high school graduates, conducted by the National Statistical Office (Istat) every four years. ${ }^{5}$ The aim of the SPHG is to collect retrospective information on the academic and professional careers of high school graduates four years after their upper secondary degrees. The two waves used in this study (2011 and 2015) were collected from students graduating high school respectively in 2007 and 2011. Our dependent variable is a dummy variable taking value 1 in case a student enrolled at university after high school graduation but successively decided to drop out. The variable takes value 0 if the student that enrolls never drops out, i.e. either

\footnotetext{
${ }^{4}$ In our theoretical setting, we assume that the probability of success ( $P$ in the utility function) remains stable and is not affected by the Great Recession.

${ }^{5}$ Information about the sampling procedure is described in detail in Istat's technical reports (Istat 2011; Istat 2015)
} 
obtained a university degree or is still studying at the time of the interview. Our main explanatory variable is a dummy variable designed to properly identify the timing of the economic crisis. As the second wave of the SPHG collects information on students who graduated from high school in 2011, interview subjects could only enroll at university (and potentially withdraw) after the crisis started in 2009. Hence, our crisis-variable takes value 1 for all students interviewed the second wave. As the first wave was conducted in 2011 on high school graduates of 2007, it comprises students that experienced the crisis during their university studies. As a result, we decided against coding all first wave students as 0 on our crisis-variable. Instead, we extracted from first wave those students that i) enrolled in university before 2009 and dropped out during/after 2009 or ii) enrolled in university during/after 2009 that thus could only have dropped out during the crisis (likewise second-wave students). These students (1,692 individuals) were assigned value 1 on our crisis-variable. The rest of the first-wave interviewees (93.64\%) were assigned value 0 .

Our analyses compare two samples: an overall sample comprising all students who enrolled at university and a restricted sample ${ }^{6}$ (respectively 26,775 and 22,714 after listwise deletion) comprising only students who continued to university immediately after high school graduation (thus only those enrolled at university in 2007 for the first wave, and in 2011 for the second wave). In other words, the restricted sample excludes all late enrollees: a population of students more likely to dropout. The comparison between these two samples is important for our discussion, as late enrollees from the first wave could have enrolled during the crisis (crisis-variable equal to one). Considering late enrollees in our analysis could result in an overestimation of the Great Recession's effect since they show a higher propensity to drop out.

Other pivotal explanatory variables in our analysis are parental education and field of study. Fields of study are grouped into seven categories: Medicine; Law; Engineering \& Architecture; Scientific (mathematics, physics, geology, chemistry, biology and agriculture); Economics and Statistics; Social Sciences (psychology, social and political sciences) and Humanities (arts, education and languages). This coding allows us to separately identify the most remunerative fields (the first three) and compare them to the other fields. Parental education is coded following the dominance criterion (Erikson 1984) and consists of three categories: i) Compulsory education (Primary or Lower secondary degree); ii) Upper secondary degree and iii) Tertiary or Post-secondary degree.

\footnotetext{
${ }^{6}$ The analyses for the restricted sample were performed in the Adele Laboratory Istat (Laboratorio per l'Analisi dei Dati ELEmentari) in compliance with legislation concerning the confidentiality of personal data. The ADELE Laboratory is a Research data centre, a "secure" site accessible by researchers to conduct their own statistical analyses on microdata (http://www.istat.it/en/information/researchers/analysis-of-individual-data). We used Adele lab as Istat does not release the information of the time of enrolment. Results and opinions presented in this chapter are our responsibility and are not official statistics.
} 
Table 2. Descriptive statistics. Overall sample.

\begin{tabular}{|c|c|c|}
\hline & \multicolumn{2}{|c|}{ Economic crisis } \\
\hline & Pre-crisis & Post-crisis \\
\hline Dropout (\% of yes) & 10.39 & 20.60 \\
\hline \multicolumn{3}{|l|}{ Field of study } \\
\hline Medicine & 10.23 & 12.28 \\
\hline Law & 7.77 & 7.80 \\
\hline Engineering \& Architecture & 15.89 & 14.66 \\
\hline Scientific & 14.08 & 14.29 \\
\hline Economics \& Statistics & 13.54 & 12.92 \\
\hline Social sciences & 14.03 & 14.34 \\
\hline Humanities & 24.46 & 23.71 \\
\hline \multicolumn{3}{|l|}{ Parental education } \\
\hline Compulsory & 24.83 & 23.67 \\
\hline Upper secondary & 53.60 & 54.13 \\
\hline Tertiary & 21.57 & 22.20 \\
\hline \multicolumn{3}{|l|}{ Parental social class } \\
\hline Service class & 20.76 & 20.61 \\
\hline White collars & 32.56 & 32.80 \\
\hline Self-employed & 12.84 & 12.04 \\
\hline Working class & 33.84 & 34.55 \\
\hline \multicolumn{3}{|l|}{ High school track } \\
\hline Academic & 58.22 & 57.85 \\
\hline Technical & 28.55 & 21.58 \\
\hline Vocational & 13.22 & 20.57 \\
\hline \multicolumn{3}{|c|}{ Final mark lower secondary school } \\
\hline Sufficient & 10.30 & 8.91 \\
\hline Good & 28.81 & 26.93 \\
\hline Very good & 32.06 & 29.15 \\
\hline Excellent & 28.83 & 35.01 \\
\hline \multicolumn{3}{|c|}{ Final mark upper secondary school } \\
\hline $60-69$ & 20.49 & 22.75 \\
\hline $70-79$ & 25.74 & 30.30 \\
\hline $80-89$ & 23.41 & 25.63 \\
\hline $90-100$ & 30.36 & 21.32 \\
\hline Failure (\% of yes) & 10.47 & 14.56 \\
\hline Remedial exams (\% of yes) & 39.03 & 42.63 \\
\hline Sex (\% of females) & 62.06 & 61.34 \\
\hline Age (more than 23 years old) & 13.34 & 18.12 \\
\hline $\mathrm{N}$ & 12,643 & 14,132 \\
\hline
\end{tabular}


As control variables we consider: sex, age, parental social class (highest occupation between the two parents), region of residence, track followed during upper secondary school, failures during high school (yes/no), remedial exams (yes/no), and final exam grades concluding lower and upper secondary studies. Table 2 reports the descriptive statistics for students before and after the crisis (overall sample) ${ }^{7}$, showing how the incidence of drop-outs doubled in the second cohort of students and how the latter show distinctive features (especially in terms of previous scholastic career).

\subsection{Method: Propensity score matching}

As a result of the differences detected between the two groups, we resort to a propensity score matching (PSM) estimator (Rosenbaum and Rubin 1983) to determine the influence of the Great Recession on the drop-out rate among the two groups. This procedure controls for potential compositional effects that may arise by comparing enrolled students from different periods. PSM is a two-step procedure. ${ }^{8}$ In our case the first step consists in estimating for all students the probability (i.e. the propensity score) of being a student in the post-crisis period according to the set of covariates defined in sub-section 4.1. In the second step students in the post-crisis period (the "treated") are matched with students from the pre-crisis period that are most similar to them (the "controls"). Level of similarity is measured by the propensity score. A kernel algorithm combined with a caliper fixed at 0.01 was used to match treated and untreated individuals on the basis of their own propensity scores. ${ }^{9}$ We thus obtain two comparable groups, on the basis of the chosen set of observable characteristics. The set of covariates was selected in order to control for the most important personal and background features likely to affect the risk of leaving university. In the next section, we present our main results in graphical fashion by plotting the effect of the Great Recession on drop out (i.e. the difference in the drop-out probability before and after the crisis). More precisely, we estimate the quantity:

$$
\delta_{i}=E\left[Y_{i} \mid D_{i}=1, p(x)\right]-E\left[Y_{i} \mid D_{i}=0, p(x)\right]
$$

where, $\delta_{i}$ is the estimated effect for individual $I$ (the average treatment effect, ATT henceforth), $Y$ is the outcome (drop-out); $D$ the dummy variable indicating the period ( 0 meaning pre-crisis and 1 meaning post-crisis); and $p(x)$ the propensity score. To ascertain the effect of the Great Recession

\footnotetext{
${ }^{7}$ The descriptive statistics on the restricted sample, which substantially overlap those reported here, are provided in the appendix (Table A.1).

${ }^{8}$ See Caliendo and Kopeinig (2008) for further information about how to implement PSM.

${ }^{9}$ We report a set of statistics about the goodness of the matching procedure in the appendix (Tables A.5, A.6).
} 
across fields of study and social origins, we estimate separate models, stratifying according to field and parental education.

\subsection{Assumptions and sensitivity checks}

PSM relies on the assumption that we are able to observe and include in our model all the relevant factors for the phenomenon under scrutiny. We chose to analyze the SPHG data as they are particularly rich and supply a large set of covariates covering the main dimensions affecting the dropout risk. ${ }^{10}$ Valid critiques of PSM mention its inability to consider unobserved features such as, in our case, students' innate abilities and personal motivation. Thanks to SPHG we are in the position to also consider, aside the various information on the student's previous scholastic career, also the grade of the concluding exam of lower secondary education (end of $8^{\text {th }}$ grade), which can serve as a proxy for individual abilities (Contini and Triventi 2016).

Individual motivation and parental support also affect the drop-out risk. Standard surveys, such as the SPHG, generally lack a suitable measure for these factors, however. Thus, it is crucial to include a set of robustness checks to estimate the eventual bias around our estimates. We rely on the method suggested by Ichino et al. (2007) and Nannicini (2007) to test the underlying assumption of the PSM, namely the plausibility of the selection on observables. The authors suggest adding a simulated, unobservable variable $(S)$ to the model to detect changes in estimates of the treatment's effect (in our case the Great Recession). To allow the simulation, unobservable variables are set to mimic the behavior (and relevance) of observed crucial factor for the drop out risk, such as social origins and previous educational achievements. Obtained results are discussed in section 5.1.

Another important consideration is that only students who enroll at university are in the position to drop-out. The process of selection into enrollment could bias the estimates calculated for enrolled students. It is well known, in fact, that people from well-off families tend to perform better at upper secondary school and are therefore more likely to enroll in university (Argentin and Triventi 2011). As our models are based on a socially selected population, they must be interpreted as a lower bound of the true effects. We believe that detecting any statistically significant effect on the drop-out risk, even if it is just the lower bound, is relevant for policy purposes. However, we also include the results of an additional analysis that, following previous papers on the determinants of the drop-out risk in Italy (Cingano and Cipollone 2007; Di Pietro and Cutillo 2004; Ghignoni 2007), relies on a model with sample selection (Heckman 1979) to estimate the effect of the economic crisis on leaving university, using the number of available university courses at a regional level as exclusion

\footnotetext{
${ }^{10}$ The variable used to estimate the propensity score (i.e. the control variables) are those listed in Table 2 with the addition of the region of residence.
} 
restriction. ${ }^{11}$ Here, we focus on the parameters of the interaction between parental education, economic crisis and field of study.

\section{Main findings}

Figure 2 displays the first set of results - the ATTs and relative standard errors from both the general model and the models stratified according to field of study. ${ }^{12}$ Filled dots correspond to the estimates from the overall sample and hollow circles correspond to those from the restricted sample, computed excluding late enrollees.

The general model shows an increase of 9.97 percentage points (pp, henceforth) in the drop-out risk during the Great Recession. In the restricted sample the estimate is only $2.7 \mathrm{pp}$ lower. No matter the sample considered, the estimate of the effect of the economic crisis is that of an increase, which is statistically significant and with a remarkable size. This result concurs with $\mathrm{Hla}$, meaning that the negative effect on university persistence attributed to the increase in direct costs exceeded the positive effects attributable to decreasing opportunity costs.

Figure 2 also allows us to analyze the effect of the Great Recession on withdrawals by field of study. In this case as well, the estimates from both samples show similar behavior and do not lead us to substantially different conclusions. First, in the overall sample, the drop-out rate in the postcrisis period clearly increased for every field. This also means that none of the fields leading to liberal professions (Medicine, Law and Engineering \& Architecture) were able to protect students from the increased drop out risk. Apparently, the rising incidence of withdrawal more strongly affected the fields of Law and Engineering \& Architecture, which show changes of more than $10 \mathrm{pp}$ in the overall sample and the highest increases in the restricted sample (+7.5 for Law and +7.4 for Engineering \& Architecture). Despite the higher scores, however, the increases in these fields following the crisis does not significantly differ from those in less remunerative fields for both the overall and the restricted samples. ${ }^{13}$ On the contrary, Medicine, where also health professions are to be found, stands out as the field being significantly less affected. As we are going to discuss more in depth in the

\footnotetext{
11 Data for our Heckman selection models come from the Atlante Statistico Territoriale delle Infrastrutture (http://asti.istat.it/asti/) maintained by the national statistical office. Average values between 2007 and 2011 were considered for the first wave and between 2011 and 2012 for the second wave for each indicator. ATLAS data are only available until 2012. The number of faculties and degree courses after the implementation of the Bologna Process in Italy (2001) showed a substantial stability over time.

${ }^{12}$ All the results are presented graphically, while the tables with the full estimates are reported in the appendix (Tables A.2, A.3, A.4 and A.7).

${ }^{13}$ Nonetheless it is interesting to observe for them the highest point estimate. The striking post-crisis increase recorded by such prestigious fields will be discussed again below, as we are going to see how it depends from a disproportionally high drop-out rate for students from less advantaged families.
} 
concluding section, this result is likely to depend on a lower sensitivity of this field to economic vicissitudes.

Figure 2. Effect of the economic crisis on drop-out probability according to field of study. PSM estimates.

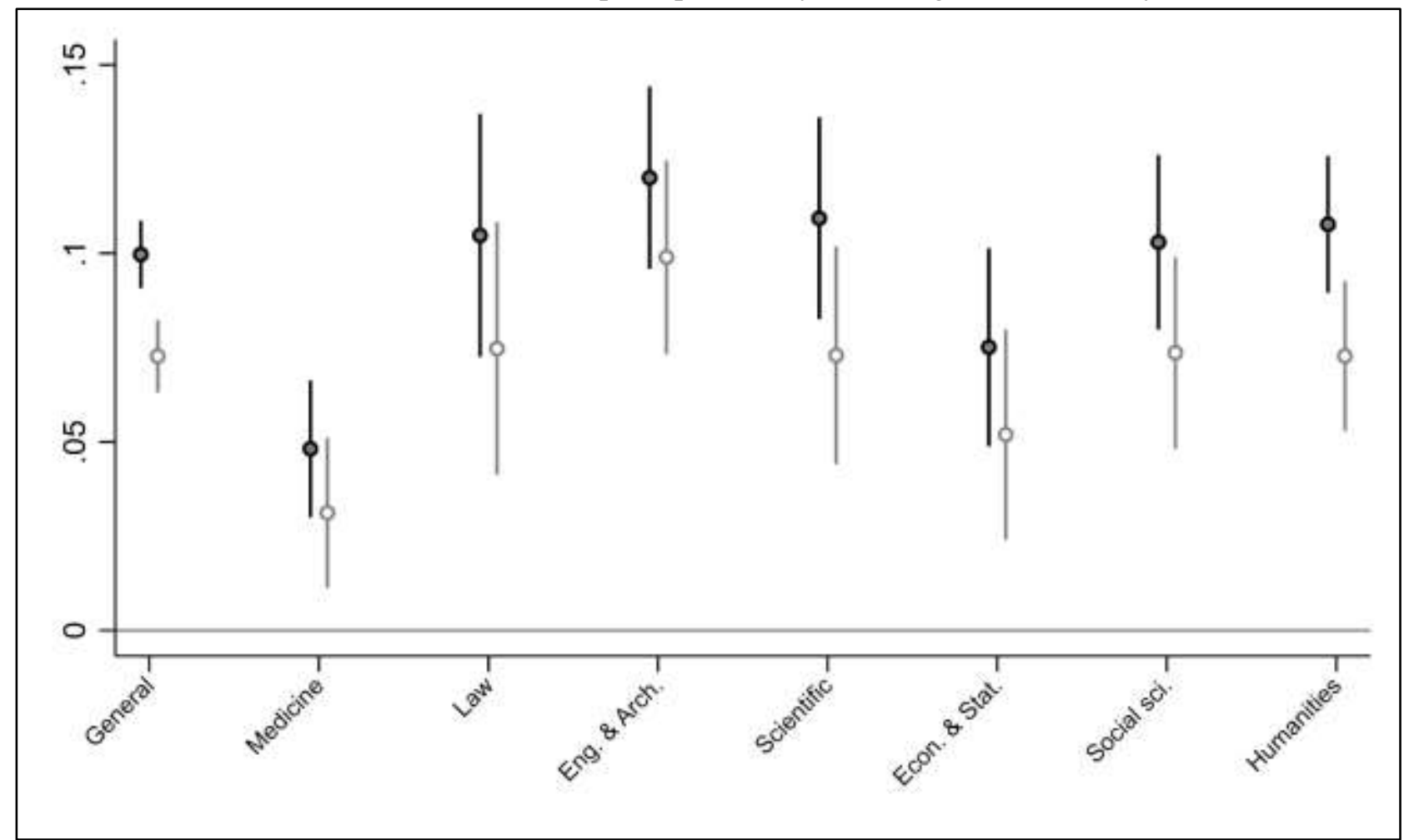

Note: The figure shows the ATT estimates and the corresponding 95\% confidence intervals according to model 1 from the previous section. Filled dots represent the effects on the whole sample, while hollow circles represent estimates for students who enrolled at the university immediately after obtaining their high school diploma.

Economic \& Statistics also appears to deviate from the general pattern of other fields. The relative low increase in drop-outs $(+7.5$ for the overall and +5.2 for the restricted sample) might be explained by the slight advantage that graduates with degrees in Economics ${ }^{14}$ have on the labor market in terms of number of positions that they could fill. According to Unioncamere (2012) ${ }^{15}$, employers in the Italian private sector, which is dominated by small and medium-sized enterprises, tend to perceive an Economics degree as a signal of greater flexibility and trainability due to the mix of technical skills students develop during their studies. To sum up, despite some signs in the direction of the hypothesis that the worst influence of the economic crisis on drop-outs is exhibited by the most prestigious fields $(H 2 a)$, the empirical evidence does not fully corroborate this hypothesis because of the outlier behavior showed by Medicine in particular.

\footnotetext{
${ }^{14}$ According to AlmaLaurea (https://www.almalaurea.it/en), an Interuniversity Consortium that represents approximately $90 \%$ of Italian graduates, there are far fewer bachelor's degrees awarded annually in Statistics (less than 1,000) than in Economics (more than 20,000). Therefore, the Economics \& Statistics field is mainly composed by students studying Economics.

${ }^{15}$ Unioncamere is the Italian public office that legally represents all the local chambers of commerce.
} 
Figure 3 shows the influence of the Great Recession according to both field of study and parental education. Fields leading to liberal professions, those which grant the best labor market returns in Italy (Ballarino and Bratti 2009; Triventi et al. 2017; Vergolini and Vlach 2017), are highlighted in panel A. Panel B shows the estimates for all other fields.

The comparison between the two panels clearly shows how the disproportional effect of the Great Recession on drop-outs according to social background, characterized prestigious fields the most ${ }^{16}$, bringing empirical evidence in favor of $H 3$. In fact, the rising incidence of withdrawals more strongly affects less-advantaged students in the fields of Medicine, Law and Engineering \& Architecture. In these fields, the drop-out increase after the crisis is, on average, more than 3.5 times higher for students with the least educated parents than that of students whose parents obtained tertiary education, a statistically significant difference.

For every other field, the estimated effects of the crisis are virtually parallel across all levels of parental education. Nonetheless we can see a general tendency for students of well-educated parents to show the lowest drop-out rate (in all but the Scientific and the Economics \& Statistic fields). An in-depth examination of the prestigious fields Law and Engineering \& Architecture shows a dramatic increase in the post-crisis drop-out rate for students with parents who only completed compulsory education (circa $20 \mathrm{pp}$ ), while the rate increased less than $5 \mathrm{pp}$ for students from advantaged families. This shows how the higher drop-out rate from these two fields showed by Figure 2 was not homogeneously distributed across social origins. Instead, our evidences suggest that the discussed noticeable increase in drop-outs after the crisis mainly depends on the behavior of the lest-advantaged students who were pursuing the most prestigious educational choices. Were especially these students that have been over-proportionally expelled from university by the Great Recession with respect to their more advantaged peers.

\footnotetext{
${ }^{16}$ In general, the point estimates for students enrolling right after the Diploma are smaller than those from the overall sample, confirming the higher drop-out propensity of late enrollees. However, the differences are also small and not statistically significant.
} 
Figure 3. Effect of the economic crisis on drop-out probability according to parental education, field of study and economic crisis. PSM estimates.

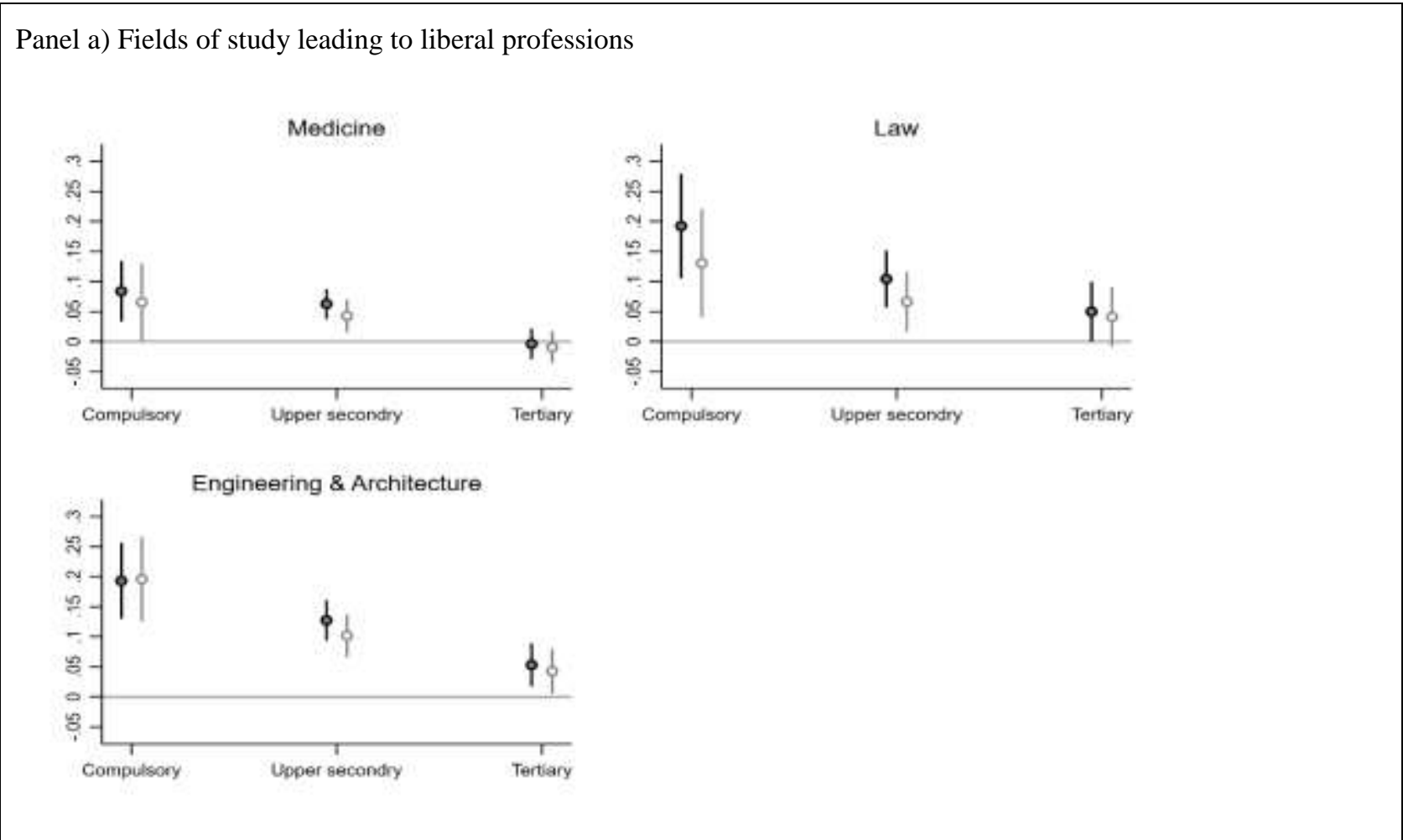

Panel b) Other fields
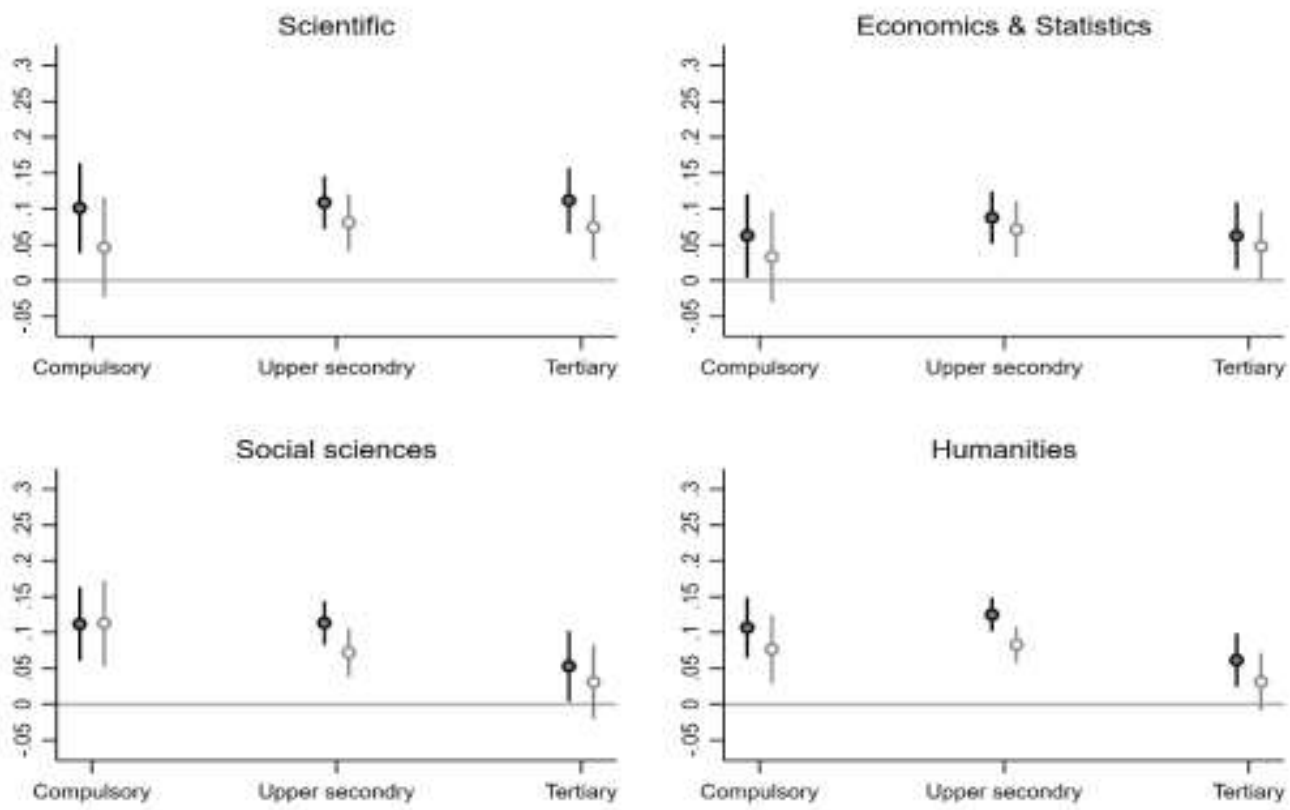

Note: The figure shows the ATT estimates and the corresponding 95\% confidence intervals according to model 1 from the previous section. Filled dots represent the effects on the whole sample, while hollow circles represent estimates for students who enrolled at the university immediately after obtaining their high school diploma. 


\subsection{Sensitivity checks}

According to the discussion on the assumptions underlying our analytical strategy (session 4.3), we supply now the results of a set of robustness checks for the estimates presented so far. Specifically, this section addresses two main sources of bias: i) potentially unobservable factors; and ii) sample selection. Due to the remarkable similarity between the results from the overall and restricted samples, the analysis in this section relate only to the overall sample.

To test the plausibility of the selection on observables assumption underlying PSM we rely on the strategy depicted in Ichino et al. (2007) and use the Stata routine sensatt designed by Nannicini (2007). This strategy applies a simulation procedure to mimic the bias resulting from unobservable factors, relying on the distribution of observed variables. In other words, we estimate the bias of unobserved factors as if they could affect the drop-out rate in a way similar to the most relevant variables (such as parental education and the previous school career). Since the routine requires dummy variables, the original variables were recoded as dummies for the simulations and used them one by one to estimate the effect of an unobservable variable. Table 3 shows the average of the simulated ATT obtained by repeating each simulation 500 times. Table 3 shows both the original ATT of models in Figure 2 together with the corresponding ATT simulated in presence of potential unobserved confounders $(S)$. On the basis of these two quantities the percentage of potential bias in the original model is computed. ${ }^{17}$ The first rows in the table present estimates for the general model, while the following rows refer to the models stratified by field of study. Additional statistics are also reported in the table. The first is the "outcome effect", or the average odds ratio of the unobserved variable $(S)$ resulting from the following logit model: $\operatorname{Pr}(Y=1 \mid D=0, S, W)$, where $Y$ is the outcome, $D$ is the treatment status, $S$ is the unobserved variable and $W$ is a set of control variables. The "selection effect" is the average odds ratio resulting from $\operatorname{Pr}(D=1 \mid S, W)$. For example, if the unobserved variable $S$ was distributed like the observed variable sex (i.e., male) in the general model, we would have observed a positive effect on the chance of being in the post-crisis period $(1.036>1)$ and also a positive effect on the risk of dropping-out $(1.617>1)$. In this case, the effect of the economic crisis would hardly be lower than the ATT estimated through the propensity score matching estimator (0.098 vs 0.100$)$. The other simulations show that potential unobserved confounders do not substantially affect our main findings and that the higher biases are related to factors connected to school career. More precisely, for the general model the simulated estimates range from 0.093 to 0.102 and the highest bias is $6.6 \%$. The results are also satisfying for the analyses stratified according to the field of study.

\footnotetext{
${ }^{17}$ Bias is computed according the following formula: $\%$ bias $=(($ ATT no confounder-ATT confounderlike $) /$ ATT no confounder) $\cdot 100$.
} 
Table 3. Sensitivity analysis of the effect of the economic crisis on dropout. Overall sample.

\begin{tabular}{lcccr}
\hline Estimates for the general model & Outcome effect & Selection effect & ATT & \% of bias \\
Confounderlike & & & & \\
No confounder & & & 0.100 & 1.606 \\
Sex & - & - & 0.098 & 0.602 \\
High parental education & 1.617 & 1.036 & 0.099 & 2.410 \\
Good final mark in lower secondary school & 0.577 & 1.051 & 0.102 & 1.406 \\
Academic track & 0.341 & 1.173 & 0.101 & 5.622 \\
No grade retention & 0.289 & 1.109 & 0.094 & 6.627 \\
Good final mark in upper secondary school & 0.422 & 0.683 & 0.093 &
\end{tabular}

Good final mark in upper secondary school

0.464

5.622

Estimates according field of study

Confounderlike, Medicine

No confounder

Sex

1.

0.385

0.118

Good final mark in lower secondary school

Academic track

No grade retention

Good final mark in upper secondary school

Confounderlike, Law

Sex

High parental education

Good final mark in lower secondary school

Academic track

No grade retention

Good final mark in upper secondary school

Confounderlike, Engineering \& Architecture

Sex

High parental education

Good final mark in lower secondary school

Academic track

No grade retention

Good final mark in upper secondary school

Confounderlike, Scientific

Sex

High parental education

Good final mark in lower secondary school

Academic track

No grade retention

Good final mark in upper secondary school

Confounderlike, Economic \& Statistics

Sex

High parental education

Good final mark in lower secondary school

Academic track

No grade retention

Good final mark in upper secondary school

Confounderlike, Social Sciences

Sex

High parental education

Good final mark in lower secondary school

Academic track

No grade retention

Good final mark in upper secondary school
0.225

0.403

0.413

$\stackrel{-}{0.901}$

0.490

0.293

0.279

0.328

0.525

2.628

0.539

0.279

0.096

0.358

0.431

$-$

1.982

0.577

0.225

0.245

0.438

0.384

1.565

0.719

0.485

0.430

0.601

0.470

1.354

0.686

0.356

0.367

0.358

0.484
- 211

1.340

1.588

1.408

0.867

0.979

${ }^{-}-\overline{018}$

0.995

1.126

0.968

0.872

0.811

1.007

1.067

1.156

1.024

0.495

0.689

0.965

0.954

1.102

1.187

0.647

0.715

$-$

1.084
1.055

1.203

0.990

0.562

0.704

$-$

0.831

1.019

1.104

1.145

0.737

0.752
0.048

0.045

0.047

0.052

0.049

0.045

0.045

6.250

2.083

8.333

2.083

6.250

6.250

0.105

$0.103 \quad 1.905$

$0.103 \quad 1.905$

$0.106 \quad 0.952$

$0.102 \quad 2.857$

$0.101 \quad 3.810$

$0.101 \quad 3.810$

0.120

$0.117 \quad 2.500$

$0.118 \quad 1.667$

$0.121 \quad 0.833$

$0.118 \quad 1.667$

$0.108 \quad 10.000$

$0.109 \quad 9.167$

0.109

$0.104 \quad 4.587$

$0.103 \quad 5.505$

$0.108 \quad 0.917$

$0.110 \quad 0.917$

$0.098 \quad 10.092$

$0.095 \quad 12.844$

0.075

0.074

0.076

0.078

0.076

0.072

0.067

1.333

1.333

4.000

1.333

4.000

10.667

0.103

0.105

0.105

0.106

0.107

0.098

0.100 
A second critical issue regards the potential selection of our sample, which only comprises enrolled students. As a robustness check we now re-estimated our models applying the strategy suggested by Heckman (1979). More precisely, following previous papers on the determinants of drop-out risk in Italy (Cingano and Cipollone 2007; Di Pietro and Cutillo 2004; Ghignoni 2007) we compute a selection model using as endogenous variables the availability of university courses at the regional level. We estimate our model considering the interaction between field of study and economic crisis. ${ }^{18}$

Figure 4. Effect of the economic crisis on drop-out probability according to field of study. Heckman selection model. Overall sample.

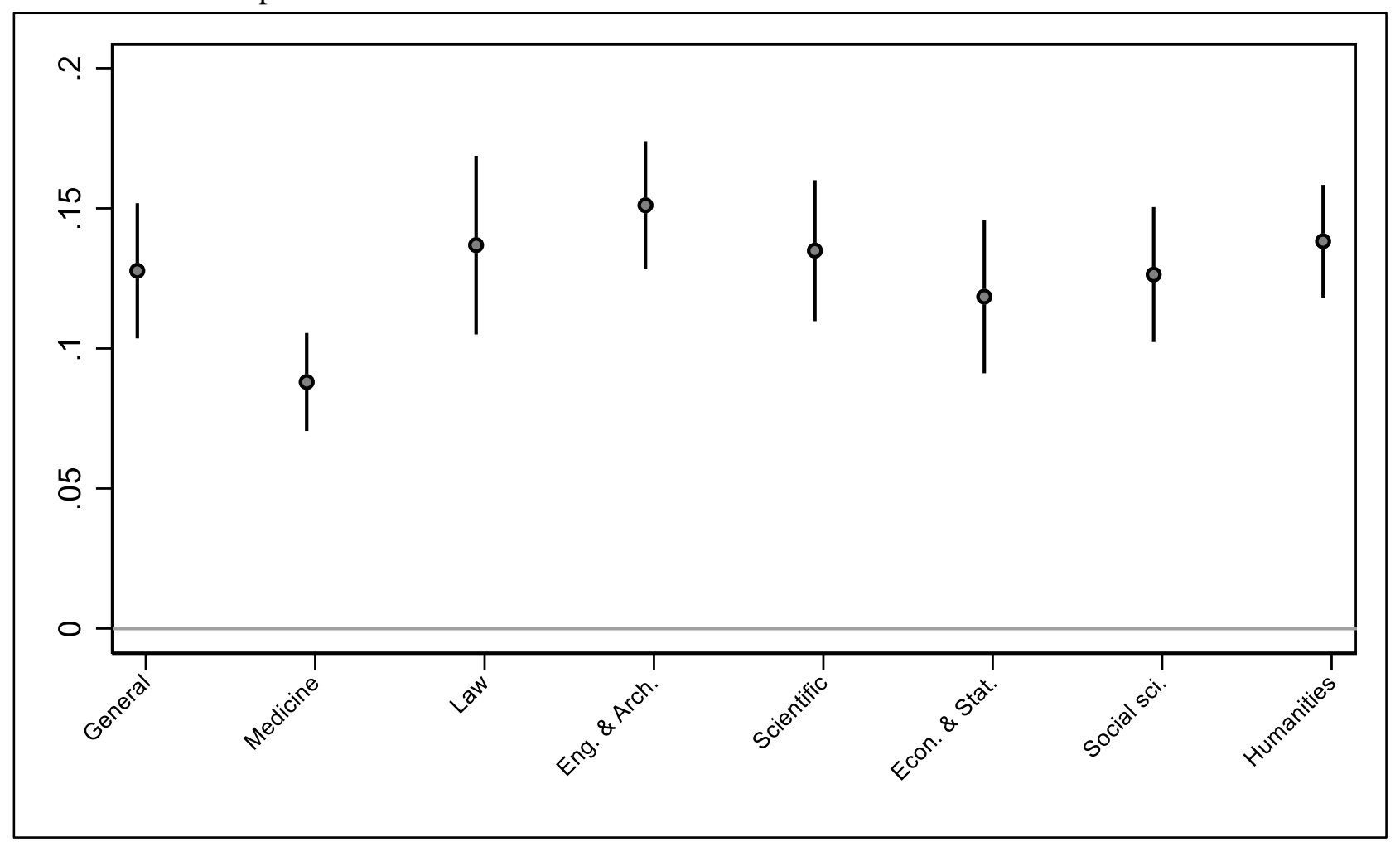

Note: the figure reports the estimates from the Heckman selection model and the corresponding $95 \%$ confidence intervals.

\footnotetext{
${ }^{18}$ Unfortunately, the information on the number of university courses is not available by fields of study. As a result, we could not carry out separate analyses according to the field of study and we are forced instead to relay on the parameters of the interaction between fields and the crisis-variable. We are convinced that, despite this representing a suboptimal solution, it allows us to retrieve important information on how our results could be affected by selection bias, which could not be obtained otherwise.
} 
Figure 4 shows the results of the Heckman selection model. As predicted, the estimates from propensity score matching on the sample of enrollees constitute the lower bound of the true parameters. However, the results depicted in Figure 4 appear coherent and similar to the main findings, except for the Economic \& Statistics field. Indeed, the increase in the post-crisis drop-out risk from this field now tracks better with that of the other fields not leading to liberal professions.

\section{Conclusions}

In this paper, our main interest lays on the influence of the Great Recession on university withdrawals and the resulting impact on social inequalities in the long run. The phenomenon of university dropout is a source of great concern in Western countries, and even more so in Italy, given the worryingly high numbers involved and the tendency of Italian employers to perceive dropping-out from university as a signal of lower productivity compared to people who never enrolled (Ghignoni et al. 2018). Our evidences suggest that the decrease in the economic prosperity caused by the Great Recession exacerbated the situation, to the greater detriment of students from less-advantaged families.

From a theoretical point of view, the effect of the Great Recession on university participation is particularly interesting. While both the direct and the opportunity costs have a negative effect on university participation (and persistence) in normal times, during recessions the increase in direct costs could lower participation (thus increase drop-outs) while the decrease in opportunity costs due to greater youth unemployment could translate into increased enrolments and fewer withdrawals. Our results suggest that the decrease in opportunity costs was not enough to compensate for the dramatic increase in direct costs. During the Great Recession the drop-out rate increased by almost 10 percentage points over the pre-crisis period, according to Hla. Hence, our study finds no empirical support for the "warehouse hypothesis", in line with the recent findings of Schizzerotto et. al. (2018) on the impact of the Great Recession on university enrollment. Thus, the Italian case seems to contradict the procyclical trend of university participation observed in other countries during the Great Recession (Lindemann and Gangl 2019; Hsin et al. 2018), although the country aligned with the international trend during the Great Depression of the 1930s (Barbagli, 1974). The combination of the empirical evidences collected so far seems to suggest that the effect of economic downturns on university participation is not constant across countries and cohorts.

In addition, this paper contributes to the debate in that it considers the horizontal dimension of educational inequality as well, by examining differences in the drop-out rate during the Great Recession according to field of study. What we find is that in the aftermath of the economic crisis every field of study experienced an increased drop-out rate. In other words, no field of study 
succeeded in fully protecting its enrolled students from dropping out as a result of the Great Recession. The most remunerative (and more expensive) fields of study recorded the highest increases in the drop-out rate in the post-crisis period (corresponding to +9.9 percentage points for Engineering \& Architecture and +7.5 for Law in the restricted sample), according to $H 2 a$. However, this hypothesis is not fully corroborated as, within the cluster of fields leading to liberal professions, one field (Medicine) stands out as having the lowest increase in the drop-out rate (5 percentage points in the overall sample and only 3.5 in the restricted). Medicine represents however a rather unique case, as the admission procedure is more competitive than in any other field in Italy (as a result of a limited number of universities hosting Medicine departments, institutional limits on enrollment numbers and a very demanding entrance examination). Moreover, graduates from this field have the highest economic returns in the country, a finding that proved to be consistent over time (Ballarino and Bratti 2009; Vergolini and Vlach 2017; Triventi et al. 2017). Hence, both university participation and labor market returns of Medicine are less sensitive to economic vicissitudes that other fields of study in Italy. On the one hand, the demand for graduates from health disciplines is likely to remain stable regardless of economic conditions (unlike for graduates of fields such as Architecture). On the other hand, it has to be considered that the main employer of graduates from the medical field in Italy is the state itself, and the Italian public sector has frequently behaved in an anti-cyclical fashion. On the contrary, graduates from other remunerative fields such as Law and Engineering are mainly employed in the private sector, which instead behaves pro-cyclically.

Finally, this study also aims at contributing to the debate by analyzing the potential long-term effects of the Great Recession on social inequality. Our analysis of the effect of the economic crisis on university drop-out according to parental education and field, shows that students from lessadvantaged backgrounds on a positive path of upward social mobility (those pursuing degrees in fields leading to liberal professions) were those the most affected by the deterioration of economic prosperity brought about by the Great Recession. In the fields of Law, Architecture and Engineering, students with less educated parents showed an increase in the drop-out rate nearly four times higher than that of their peers with tertiary educated parents. As Italy has the lowest rate of tertiary education competition after a drop-out episode (6.1\%) among European countries (Schnepf 2017) and as in this country a withdrawal carries severe consequences for labor market opportunities, we conclude that the Great Recession exerted a strong effect on social inequality by reducing upward mobility chances of students from less advantaged families in the long run, according to $H 3$.

With respect to the debate around financial aid in higher education, our results stress the role of direct costs and their relevance in families' crucial decisions during economic downturns. In fact, the evaluations previously conducted on the impact of grants provided under the "Right to Education" 
program in Italy report a negative causal effect (i.e., a reduction) on the drop-out rate, (Mealli and Rampichini 2012; Modena et al. 2018; Facchini et al. 2019). Policy makers should consider implementing programs similar to the "Right to Education" to limit the increase in withdrawals from university or, alternatively, ad hoc measures designed to address the differential effects of increasing direct costs across socials classes.

\section{References}

Aina, Carmen. 2013. "Parental background and university dropout in Italy." Higher Education 65(4): 437-456.

Adamopoulou, E Effrosyni and Giulia Tanzi. 2017. "Academic Performance and the Great Recession." Journal of Human Capital 11(1): 35-71.

Argentin, Gianluca and Moris Triventi. 2011. "Social inequality in higher education and labour market in a period of institutional reforms: Italy, 1992-2007." Higher Education 61(3): 309-323.

Ballarino, Gabriele and Massimiliano Bratti. 2009. "Field of study and university graduates' early employment outcomes in Italy during 1995-2004." Labour 23(3): 421-457.

Barbagli, Marzio. 1974. Disoccupazione intellettuale e sistema scolastico in Italia (1859-1973). Bologna: Il Mulino.

Barr, Andrew and Sarah Turner E. 2013. "Expanding Enrolments and Contracting State Budgets: the Effect of the Great Recession on Higher Education." The Annals of the American Academy of Political and Social Sciences 650: 168-193.

Becker, Rolf and Anna Hecken E. 2009. „Higher education or vocational training? An empirical test of the rational action model of educational choices suggested by Breen and Goldthorpe and Esser." Acta Sociologica 52(1): 25-45.

Brandolini, Andrea, Francesco D'Amuri and Ivan Faiella. 2013. "Country case study - Italy." In The Great recession and the Distribution of Household Income, edited by Jenkins Stephen P., Andrea Brandolini, John Micklewright and Brian Nolan. Oxford: Oxford University Press.

Breen, Richard and John Goldthorpe H. 1997. "Explaining Education Differentials. Towards a formal rational action theory." Rationality and Society 9(3): 275-305.

Breen, Richard and Jan Jonsson O. 2005. "Inequality of opportunity in comparative perspective: Recent research on educational attainment and social mobility." Annu. Rev. Sociol 31: 223-243.

Caliendo, Marco and Sabine Kopeinig. 2008. "Some practical guidance for the implementation of propensity score matching." Journal of Economic Surveys 22(1): 31-72.

Christie, Hazel, Moira Munro and Tania Fisher. 2004. "Leaving university early: Exploring the differences between continuing and non-continuing students." Studies in Higher Education 29(5): 617-636.

Cingano, Federico and Piero Cipollone. 2007. "University drop-out: The case of Italy." Temi di discussione Banca d'Italia No. 626.

Contini, Dalrit and Moris Triventi. 2016. "Between formal openness and stratification in secondary education: Implications for social inequalities in Italy", in Models of Secondary Education and Social Inequality: An International Comparison, edited by Blossfeld, Hans-Peter, Sandra Buchholz, Jan Skopek and Moris Triventi, pp. 305-322. Cheltenham, UK: Edward Elgar,

Crawford, Claire. 2014. "Socio-economic differences in university outcomes in the UK: drop-out, degree completion and degree class." IFS Working Papers No. W14/31.

D'Amuri, Francesco. 2011. "The impact of the Great Recession on the Italian labour market". In Who Loses in the Downturn? Economic Crisis, Employment and Income Distribution, pp. 155-180. Emerald Group Publishing Limited. 
Di Pietro, Giorgio. 2004. "The determinants of university dropout in Italy: A bivariate probability model with sample selection.” Applied Economics Letters 11: 187-191.

Di Pietro, Giorgio. 2012. "The Bologna Process and widening participation in university education: new evidence from Italy." Empirica 39: 357-374.

Di Pietro, Giorgio and Andrea Cutillo. 2008. "Degree flexibility and university drop out: The Italian experience." Economics of Education Reviews 27: 546-555.

Erikson, Robert. 1984. "Social Class of Men, women and Families." Sociology 18(4): 500-514.

Facchini, Marta, Moris Triventi and Loris Vergolini. 2019. "Do Grants Improve the Outcomes of University Students in a Context with High Dropout Rates? Evidence from a Matching Approach." SocArXiv April 8.

Ghignoni, Emanuela. 2017. "Family background and university dropouts during the crisis: the case of Italy." Higher Education 73(1): 127-151.

Ghignoni, Emanuela, Giuseppe Crocea and Alessandro d'Ambrosio. 2019. "University dropouts vs high school graduates in the school-to-work transition: Who is doing better?" International Journal of Manpower 40(3): 449-472.

Grusky, David B., Bruce Western and Christopher Wimer. 2011. The Great Recession. New York: Russell Sage Foundation.

Gury, Nicolas. 2011. "Dropping out of higher education in France: a micro-economic approach using survival analysis" Education Economics 19(1): 51-64.

Hanushek, Eric A. and Ludger Woessmann. 2008. "The role of cognitive skills in economic development." Journal of economic literature 46(3): 607-68.

Hanushek, Eric A. and Ludger Woessmann. 2012. "Do better schools lead to more growth? Cognitive skills, economic outcomes, and causation." Journal of economic growth 17(4): 267-321.

Heckman, James J. 1979. "Sample selection bias as a specification error." Econometrica: Journal of the econometric society 153-161.

Hout, Michael and Thomas Di Prete, A. 2006. "What we have learned: RC28's contributions to knowledge about social stratification." Research in social stratification and mobility 24(1): 1-20.

Hsin, Amy, Lizandra Friedland and Jessica Hardie H. 2018. „Higher Education During Economic Crisis: The Effect of the Great Recession at a Large Public University", working paper.

Ichino, Andrea, Fabrizia Mealli and Tommaso Nannicini. 2008. "From temporary help jobs to permanent employment: what can we learn from matching estimators and their sensitivity?" Journal of applied econometrics 23(3): 305-327.

Jenkins Stephen P., Andrea Brandolini, John Micklewright and Brian Nolan. 2013. The Great recession and the Distribution of Household Income. Oxford: Oxford University Press.

Lassibille, Gérard and Lucia Navarro Gómez. 2008. "Why do higher education students drop out? Evidence from Spain." Education Economics 16(1): 89-105.

Lucas, Samuel R. 2001. "Effectively maintained inequality: education transition, track mobility, and social background effects." American Journal of Sociology 106(6): 1642-1690.

Mealli, Fabrizia and Carla Rampichini. 2012. "Evaluating the effects of university grants by using regression discontinuity designs." Journal of the Royal Statistical Society, Series A (Statistics in Society) 175(3): 775-798.

Modena, Francesca, Tanzi, Giulia and Enrico Rettore. 2018. The effect of grants on university dropout rates: evidence on the Italian case (No. 1193). Bank of Italy, Economic Research and International Relations Area.

Nannicini, Tommaso. 2007. "Simulation-based sensitivity analysis for matching estimators." The STATA Journal 7 (3): 334-350.

OECD. 2018. Education at a Glance 2018: OECD Indicators. Paris: OECD Publishing.

Pisati, Maurizio. 2002. La partecipazione al sistema scolastico. In Vite ineguali. Disuguaglianze e corsi di vita nell'Italia contemporanea, edited by Schizzerotto, Antonio, pp. 141-186. Bologna: Il Mulino. 
Reimer, David, Clemens Noelke and Aleksander Kucel. 2008. „Labor market effects of field of study in comparative perspective: An analysis of 22 European countries." International Journal of Comparative Sociology 49(4-5): 233-256.

Reinhart, Carmen M. and Kenneth Rogoff S. 2009. This time is Different: Eight centuries of Financial Folly. Princeton, NJ: Princeton University Press.

Rosenbaum, Paul R. and Donald Rubin B. 1983. „The central role of the propensity score in observational studies for causal effects." Biometrika 70 (1): 41-55.

Schizzerotto, Antonio, Giovanni Abbiati and Loris Vergolini. 2018. Espansioni e contrazioni della partecipazione scolastica in Italia dall'inizio del XX secolo ad oggi. Il ruolo delle riforme scolastiche e delle vicende economiche. In La società italiana e le grandi crisi economiche. 19292016, edited by Istat, pp. 95-118, Roma: Istat.

Schnepf, Sylke V. 2017. "How do tertiary dropouts fare in the labour market? A comparison between EU countries." Higher Education Quarterly 71(1): 75-96.

Smith, Jeremy P. and Robin Naylor, A. 2001. "Dropping out of university: a statistical analysis of the probability of withdrawal for UK university students." Journal of the Royal Statistical Society: Series A (Statistics in Society) 164(2): 389-405.

Stocké, Volker. 2019. "The rational choice paradigm in the sociology of education." Research Handbook on the Sociology of Education 57.

Stratton, Leslie S., Dennis O'Toole M. and James Wetzel N. 2008. "A multinomial logit model of college stopout and dropout behavior." Economics of education review 27(3): 319-331.

Tinto, Vincent. 1975. "Dropout from higher education: A theoretical synthesis of recent research." Review of educational research 45(1): 89-125.

Tinto, Vincent. 2006. "Research and practice of student retention: What next?" Journal of College Student Retention: Research, Theory \& Practice 8(1): 1-19.

Triventi, Moris and Trivellato, Paolo. 2009. "Participation, performance and inequality in Italian higher education in the 20th century." Higher Education 57(6): 681-702.

Triventi, Moris, Loris Vergolini, \& Zanini, N. 2017. "Do individuals with high social background graduate from more rewarding fields of study? Changing patterns before and after the 'Bologna process'." Research in Social Stratification and Mobility 51: 28-40.

Unioncamere 2012. Laureati e lavoro, Roma: Unioncamere.

Vergolini, Loris and Eleonora Vlach, E. 2017. "Family background and educational path of Italian graduates." Higher Education 73(2): 245-259. 


\section{Appendix}

This appendix reports a set of descriptive statistics (Table A.1), the tables with the full estimates (Tables A.2, A.3, A.4 and A.7) and a set of statistics for evaluating the goodness of matching (Tables A.5, A.6). More precisely, we compare the unmatched and the matched samples looking at three statistics. First, we calculate the pseudo- $\mathrm{R}^{2}$ for the probability of being treated in the two samples. If the matching works good, we will expect to find a very low pseudo-R2 meaning that the observed covariates lose their explanatory power after the matching. Second, we calculate the mean and median bias that can be intended as an indicator that assesses the distance between treated and controls for all the covariates. Also in this case, if the matching succeeds, we should observe a huge reduction in the bias.

All these statistics indicate that the matching procedure was able to create two equivalent groups on the basis of observed characteristics. The pseudo- $\mathrm{R}^{2}$ is not statistically different from 0 in the matched sample and the mean and median bias drop dramatically after matching. 
Table A1. Descriptive statistics. Restricted sample.

\begin{tabular}{|c|c|c|}
\hline & & \\
\hline & Pre-crisis & Post-crisis \\
\hline Dropout (\% of yes) & 11.34 & 17.97 \\
\hline Field of study & & \\
\hline Medicine & 9.84 & 11.70 \\
\hline Law & 8.02 & 8.46 \\
\hline Engineering \& Architecture & 16.27 & 15.52 \\
\hline Scientific & 14.25 & 14.31 \\
\hline Economics \& Statistics & 13.79 & 13.27 \\
\hline Social sciences & 13.74 & 14.07 \\
\hline Humanities & 24.09 & 22.68 \\
\hline Parental education & & \\
\hline Compulsory & 24.29 & 21.80 \\
\hline Upper secondary & 53.79 & 54.16 \\
\hline Tertiary & 21.92 & 24.04 \\
\hline Parental social class & & \\
\hline Service class & 21.04 & 21.36 \\
\hline White collars & 32.80 & 33.86 \\
\hline Self-employed & 12.61 & 11.85 \\
\hline Working class & 33.54 & 32.93 \\
\hline High school track & & \\
\hline Academic & 59.42 & 63.69 \\
\hline Technical & 28.28 & 19.52 \\
\hline Vocational & 12.30 & 16.79 \\
\hline Final mark lower secondary s & & \\
\hline Sufficient & 10.05 & 6.81 \\
\hline Good & 28.06 & 24.90 \\
\hline Very good & 32.04 & 30.00 \\
\hline Excellent & 29.85 & 38.29 \\
\hline Final mark upper secondary s & & \\
\hline $60-69$ & 19.85 & 20.06 \\
\hline $70-79$ & 25.34 & 29.80 \\
\hline $80-89$ & 23.63 & 26.73 \\
\hline $90-100$ & 31.17 & 23.40 \\
\hline Failure (\% of yes) & 9.81 & 12.91 \\
\hline Remedial exams (\% of yes) & 38.37 & 40.22 \\
\hline Sex (\% of females) & 61.92 & 62.72 \\
\hline Age (more than 23 years old) & 12.55 & 16.01 \\
\hline N. & 11,590 & 11,124 \\
\hline
\end{tabular}

Source: SPHG 2011 and 2015. 
Table A2. Average Treatment Effect (ATT) of the Great Recession on university dropout, standard errors and confidence interval at $95 \%$ of confidence. PSM estimates.

\begin{tabular}{lrrrrr}
\hline & & \multicolumn{3}{c}{ Confidence interval (95\%) } & \\
& ATT & Std. Err. & Min & Max & N \\
\hline Overall sample & & & & & \\
General effect & & & & & \\
Medicine & 0.0997 & 0.0046 & 0.0907 & 0.1086 & 26,757 \\
Law & 0.048 & 0.009 & 0.030 & 0.066 & 3,016 \\
Engineering \& Architecture & 0.105 & 0.016 & 0.072 & 0.137 & 2,080 \\
Scientific & 0.120 & 0.012 & 0.096 & 0.144 & 4,059 \\
Economics \& Statistics & 0.109 & 0.014 & 0.082 & 0.136 & 3,778 \\
Social sciences & 0.075 & 0.013 & 0.049 & 0.101 & 3,514 \\
Humanities & 0.103 & 0.012 & 0.080 & 0.126 & 3,774 \\
& 0.108 & 0.009 & 0.090 & 0.126 & 6,424 \\
Restricted sample & & & & & \\
& & & & & \\
General effect & & & & & \\
Medicine & 0.0727 & 0.0049 & 0.0631 & 0.0824 & 22,665 \\
Law & 0.031 & 0.010 & 0.011 & 0.051 & 2,440 \\
Engineering \& Architecture & 0.075 & 0.017 & 0.041 & 0.108 & 1,860 \\
Scientific & 0.099 & 0.013 & 0.073 & 0.125 & 3,598 \\
Economics \& Statistics & 0.073 & 0.015 & 0.044 & 0.102 & 3,232 \\
Social sciences & 0.052 & 0.014 & 0.024 & 0.080 & 3,061 \\
Humanities & 0.074 & 0.013 & 0.048 & 0.099 & 3,144 \\
& 0.073 & 0.010 & 0.053 & 0.093 & 5,305 \\
\hline Source: SPHG 2011 & & & & & \\
\hline
\end{tabular}

Source: SPHG 2011 and 2015. 
Table A3. Average Treatment Effect (ATT) of the Great Recession on university dropout according to field of study and parental education, standard errors and confidence interval at $95 \%$ of confidence. Overall sample. PSM estimates.

\begin{tabular}{|c|c|c|c|c|c|}
\hline \multirow{2}{*}{ Overall sample } & \multirow[b]{2}{*}{ ATT } & \multirow[b]{2}{*}{ Std. Err. } & \multicolumn{2}{|c|}{ Confidence interval (95\%) } & \multirow[b]{2}{*}{$\mathrm{N}$} \\
\hline & & & Min & Max & \\
\hline \multicolumn{6}{|l|}{ Medicine } \\
\hline Compulsory & 0.084 & 0.026 & 0.033 & 0.134 & 700 \\
\hline Upper secondary & 0.063 & 0.013 & 0.037 & 0.088 & 1,515 \\
\hline Tertiary & -0.004 & 0.013 & -0.029 & 0.022 & 786 \\
\hline \multicolumn{6}{|l|}{ Law } \\
\hline Compulsory & 0.192 & 0.044 & 0.105 & 0.279 & 453 \\
\hline Upper secondary & 0.104 & 0.024 & 0.057 & 0.152 & 1,003 \\
\hline Tertiary & 0.050 & 0.025 & 0.000 & 0.099 & 610 \\
\hline \multicolumn{6}{|c|}{ Engineering \& Architecture } \\
\hline Compulsory & 0.193 & 0.032 & 0.130 & 0.256 & 860 \\
\hline Upper secondary & 0.127 & 0.017 & 0.094 & 0.161 & 2,220 \\
\hline Tertiary & 0.053 & 0.018 & 0.017 & 0.089 & 964 \\
\hline \multicolumn{6}{|l|}{ Scientific } \\
\hline Compulsory & 0.101 & 0.032 & 0.038 & 0.164 & 900 \\
\hline Upper secondary & 0.109 & 0.0189 & 0.072 & 0.146 & 2,058 \\
\hline Tertiary & 0.112 & 0.023 & 0.066 & 0.157 & 812 \\
\hline \multicolumn{6}{|c|}{ Economics \& Statistics } \\
\hline Compulsory & 0.063 & 0.030 & 0.004 & 0.121 & 828 \\
\hline Upper secondary & 0.088 & 0.019 & 0.051 & 0.124 & 1,942 \\
\hline Tertiary & 0.062 & 0.024 & 0.015 & 0.109 & 726 \\
\hline \multicolumn{6}{|l|}{ Social sciences } \\
\hline Compulsory & 0.112 & 0.026 & 0.060 & 0.163 & 991 \\
\hline Upper secondary & 0.113 & 0.016 & 0.083 & 0.144 & 2,091 \\
\hline Tertiary & 0.053 & 0.025 & 0.004 & 0.102 & 701 \\
\hline \multicolumn{6}{|l|}{ Humanities } \\
\hline Compulsory & 0.107 & 0.021 & 0.065 & 0.149 & 1,670 \\
\hline Upper secondary & 0.125 & 0.012 & 0.101 & 0.149 & 3,533 \\
\hline Tertiary & 0.061 & 0.019 & 0.024 & 0.099 & 1,208 \\
\hline
\end{tabular}

Source: SPHG 2011 and 2015. 
Table A4. Average Treatment Effect (ATT) of the Great Recession on university dropout according to field of study and parental education, standard errors and confidence interval at $95 \%$ of confidence. Restricted sample. PSM estimates.

\begin{tabular}{|c|c|c|c|c|c|}
\hline \multirow{2}{*}{ Restricted sample } & \multirow[b]{2}{*}{ ATT } & \multirow[b]{2}{*}{ Std. Err. } & \multicolumn{2}{|c|}{ Confidence interval (95\%) } & \multirow[b]{2}{*}{$\mathrm{N}$} \\
\hline & & & Min & $\operatorname{Max}$ & \\
\hline \multicolumn{6}{|l|}{ Medicine } \\
\hline Compulsory & 0.065 & 0.033 & 0.001 & 0.130 & 500 \\
\hline Upper secondary & 0.043 & 0.014 & 0.015 & 0.070 & 1,210 \\
\hline Tertiary & -0.009 & 0.013 & -0.036 & 0.017 & 704 \\
\hline \multicolumn{6}{|l|}{ Law } \\
\hline Compulsory & 0.130 & 0.046 & 0.040 & 0.221 & 388 \\
\hline Upper secondary & 0.066 & 0.026 & 0.016 & 0.116 & 893 \\
\hline Tertiary & 0.041 & 0.025 & -0.008 & 0.090 & 563 \\
\hline \multicolumn{6}{|c|}{ Engineering \& Architecture } \\
\hline Compulsory & 0.196 & 0.036 & 0.125 & 0.266 & 716 \\
\hline Upper secondary & 0.102 & 0.018 & 0.066 & 0.138 & 1,978 \\
\hline Tertiary & 0.043 & 0.019 & 0.005 & 0.080 & 888 \\
\hline \multicolumn{6}{|l|}{ Scientific } \\
\hline Compulsory & 0.046 & 0.036 & -0.024 & 0.116 & 735 \\
\hline Upper secondary & 0.081 & 0.021 & 0.041 & 0.121 & 1,766 \\
\hline Tertiary & 0.074 & 0.023 & 0.029 & 0.120 & 714 \\
\hline \multicolumn{6}{|c|}{ Economics \& Statistics } \\
\hline Compulsory & 0.033 & 0.032 & -0.031 & 0.096 & 721 \\
\hline Upper secondary & 0.071 & 0.020 & 0.032 & 0.111 & 1,681 \\
\hline Tertiary & 0.048 & 0.025 & -0.001 & 0.096 & 652 \\
\hline \multicolumn{6}{|l|}{ Social sciences } \\
\hline Compulsory & 0.113 & 0.031 & 0.053 & 0.173 & 782 \\
\hline Upper secondary & 0.072 & 0.017 & 0.039 & 0.106 & 1,734 \\
\hline Tertiary & 0.031 & 0.026 & -0.021 & 0.083 & 611 \\
\hline \multicolumn{6}{|l|}{ Humanities } \\
\hline Compulsory & 0.076 & 0.024 & 0.028 & 0.124 & 1,328 \\
\hline Upper secondary & 0.083 & 0.013 & 0.057 & 0.108 & 2,936 \\
\hline Tertiary & 0.031 & 0.021 & -0.009 & 0.072 & 1,023 \\
\hline
\end{tabular}

Source: SPHG 2011 and 2015. 
Table A.5 Goodness of the matching procedure for the general model and according to field of study.

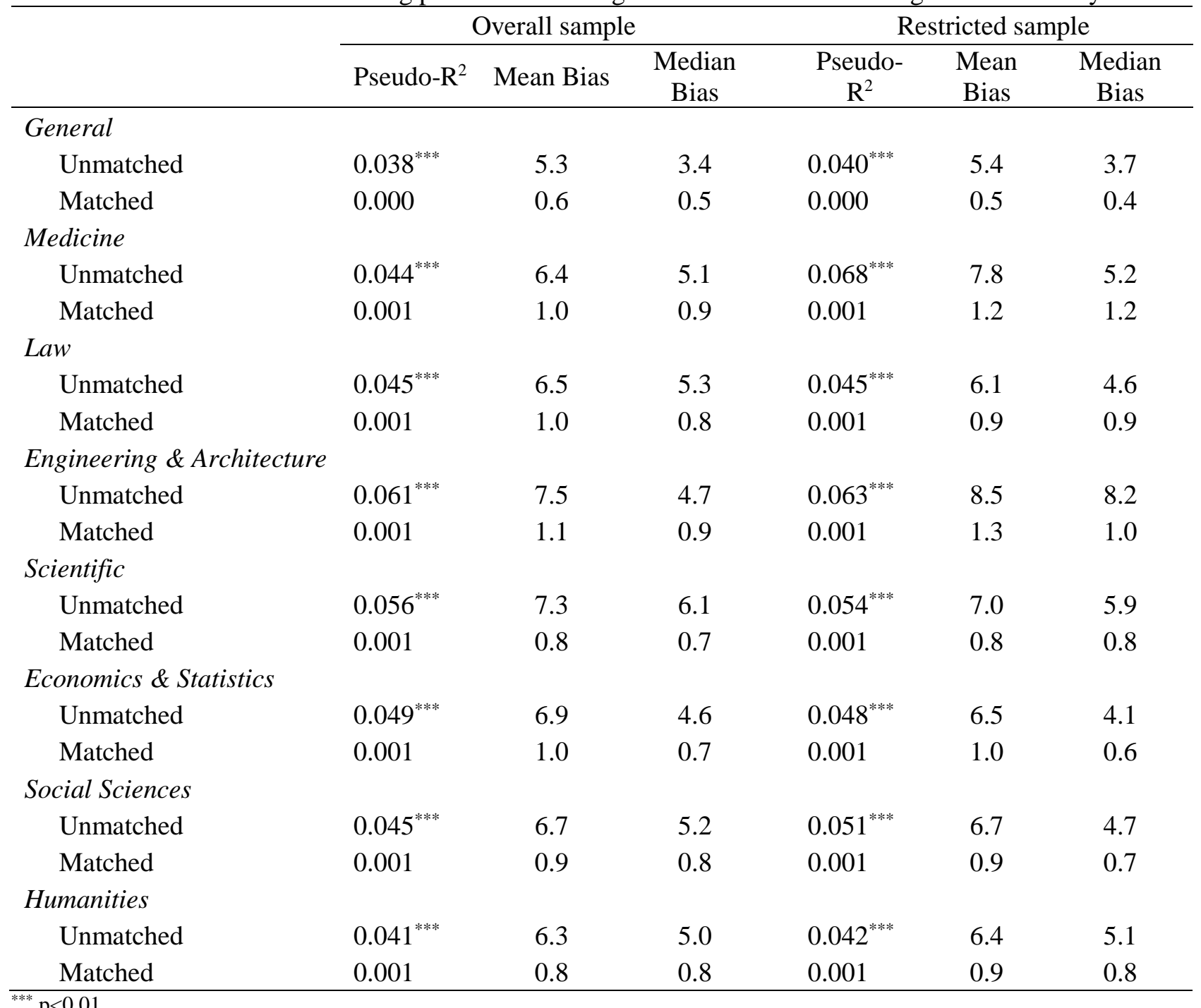

Source: SPHG 2011 and 2015. 
Table A.6 Goodness of the matching procedure according to field of study and parental education.

\begin{tabular}{|c|c|c|c|c|c|c|}
\hline \multirow{4}{*}{$\begin{array}{l}\text { COMPULSORY } \\
\text { Medicine }\end{array}$} & \multicolumn{3}{|c|}{ Overall sample } & \multicolumn{3}{|c|}{ Restricted sample } \\
\hline & \multirow[t]{2}{*}{ Pseudo-R ${ }^{2}$} & \multirow[t]{2}{*}{ Mean Bias } & \multirow[t]{2}{*}{$\begin{array}{c}\text { Median } \\
\text { Bias }\end{array}$} & \multirow[t]{2}{*}{$\begin{array}{c}\text { Pseudo- } \\
\mathrm{R}^{2} \\
\end{array}$} & \multirow[t]{2}{*}{$\begin{array}{c}\text { Mean } \\
\text { Bias }\end{array}$} & \multirow[t]{2}{*}{$\begin{array}{c}\text { Median } \\
\text { Bias }\end{array}$} \\
\hline & & & & & & \\
\hline & & & & & & \\
\hline Unmatched & $0.065^{* * *}$ & 7.6 & 5.3 & $0.122^{* * *}$ & 11.5 & 10.1 \\
\hline Matched & 0.005 & 2.2 & 2.0 & 0.011 & 3.4 & 2.6 \\
\hline \multicolumn{7}{|l|}{ Law } \\
\hline Unmatched & $0.091^{* * * *}$ & 9.6 & 7.4 & $0.092^{* * *}$ & 9.3 & 6.7 \\
\hline Matched & 0.008 & 2.6 & 2.2 & 0.007 & 2.2 & 1.7 \\
\hline \multicolumn{7}{|c|}{ Engineering \& Architecture } \\
\hline Unmatched & $0.083^{* * *}$ & 10.0 & 7.9 & $0.084^{* * *}$ & 9.6 & 6.4 \\
\hline Matched & 0.004 & 2.0 & 1.9 & 0.004 & 1.7 & 1.1 \\
\hline \multicolumn{7}{|l|}{ Scientific } \\
\hline Unmatched & $0.091^{* * *}$ & 10.1 & 7.2 & $0.099^{* * *}$ & 10.7 & 7.6 \\
\hline Matched & 0.007 & 2.8 & 1.8 & 0.009 & 3.2 & 2.1 \\
\hline \multicolumn{7}{|c|}{ Economics \& Statistics } \\
\hline Unmatched & $0.089^{* * *}$ & 10.6 & 10.2 & $0.096^{* * *}$ & 10.6 & 10.2 \\
\hline Matched & 0.009 & 2.2 & 1.6 & 0.011 & 2.1 & 1.5 \\
\hline \multicolumn{7}{|l|}{ Social Sciences } \\
\hline Unmatched & $0.070^{* * *}$ & 7.9 & 6.1 & $0.084^{* * *}$ & 8.7 & 7.9 \\
\hline Matched & 0.004 & 1.8 & 1.4 & 0.005 & 2.3 & 1.6 \\
\hline \multicolumn{7}{|l|}{ Humanities } \\
\hline Unmatched & $0.054^{* * *}$ & 7.8 & 6.3 & $0.071^{* * *}$ & 8.2 & 6.8 \\
\hline Matched & 0.004 & 1.8 & 1.5 & 0.003 & 1.6 & 1.0 \\
\hline \multicolumn{7}{|c|}{ UPPER SECONDARY } \\
\hline \multicolumn{7}{|c|}{ Medicine } \\
\hline Unmatched & $0.057^{* * *}$ & 7.6 & 6.5 & $0.078^{* * *}$ & 7.4 & 5.7 \\
\hline Matched & 0.003 & 1.8 & 1.5 & 0.002 & 1.6 & 1.3 \\
\hline \multicolumn{7}{|l|}{ Law } \\
\hline Unmatched & $0.045^{* * *}$ & 6.6 & 5.6 & $0.063^{* * *}$ & 7.5 & 6.9 \\
\hline Matched & 0.002 & 1.3 & 1.0 & 0.003 & 1.4 & 1.0 \\
\hline \multicolumn{7}{|c|}{ Engineering \& Architecture } \\
\hline Unmatched & $0.064^{* * *}$ & 8.3 & 7.3 & $0.070^{* * *}$ & 9.0 & 7.9 \\
\hline Matched & 0.002 & 1.3 & 1.1 & 0.003 & 1.9 & 1.7 \\
\hline \multicolumn{7}{|l|}{ Scientific } \\
\hline Unmatched & $0.089^{* * *}$ & 0.0 & 8.1 & $0.052^{* * *}$ & 6.9 & 5.7 \\
\hline Matched & 0.009 & 1.0 & 0.9 & 0.001 & 1.2 & 1.0 \\
\hline \multicolumn{7}{|c|}{ Economics \& Statistics } \\
\hline Unmatched & $0.056^{* * *}$ & 7.8 & 5.3 & $0.060^{* * *}$ & 7.8 & 6.8 \\
\hline Matched & 0.002 & 1.3 & 1.0 & 0.001 & 1.1 & 0.9 \\
\hline \multicolumn{7}{|l|}{ Social Sciences } \\
\hline Unmatched & $0.049^{* * *}$ & 7.3 & 6.8 & $0.061^{* * *}$ & 8.0 & 6.6 \\
\hline Matched & 0.001 & 1.1 & 0.9 & 0.001 & 1.2 & 1.0 \\
\hline
\end{tabular}

Humanities 


$\begin{array}{lllllll}\text { Unmatched } & 0.038^{* * *} & 6.4 & 5.5 & 0.036^{* * *} & 6.2 & 4.9 \\ \text { Matched } & 0.000 & 0.7 & 0.6 & 0.001 & 0.9 & 0.8\end{array}$

\section{TERTIARY}

Medicine

Unmatched

$0.059^{* * * *}$

8.3

6.4

$0.071^{* * *}$

9.5

8.2

Matched

0.003

1.6

$1.3 \quad 0.003$

1.7

Law

Unmatched

$0.097^{* * *}$

10.3

9.4

$0.076^{* * *}$

8.6

7.6

Matched

0.004

2.1

1.7

0.008

2.5

Engineering \& Architecture

$\begin{array}{lllllll}\text { Unmatched } & 0.082^{* * *} & 9.1 & 8.0 & 0.090^{* * *} & 9.7 & 9.5 \\ \text { Matched } & 0.004 & 2.1 & 2.0 & 0.005 & 2.2 & 2.0\end{array}$

Scientific

Unmatched

$0.088^{* * *}$

9.9

$10.3 \quad 0.072^{* * * *}$

8.8

9.2

Matched

0.004

1.8

1.3

0.005

2.3

1.6

Economics \& Statistics

Unmatched

$0.066^{* * *} \quad 8.0$

7.4

$0.091^{* * *}$

10.1

10.4

Matched

0.007

2.6

2.7

0.004

1.7

1.5

Social Sciences

Unmatched

$0.081^{* * *} \quad 10.3$

$9.4 \quad 0.084^{* * *}$

10.1

8.2

Matched

0.005

2.1

1.4

0.007

2.5

1.6

Humanities

Unmatched

$0.075^{* * *}$

8.9

6.8

$0.074^{* * *}$

8.8

8.1

$\frac{\text { Matche }}{{ }^{* * *} \mathrm{p}<0.01}$

0.005

2.1

$1.6 \quad 0.004$

2.0

1.9

Source: SPHG 2011 and 2015. 
Table A.7 - Effect of the economic crisis on Drop-out probability according to field of study. Heckman selection model. Overall sample.

\begin{tabular}{lll}
\hline $\operatorname{Pr}($ dropout $)$ & Coeff. & Std. Err. \\
\hline Crisis (yes) & $0.088^{* * *}$ & 0.011
\end{tabular}

Field of study

Medicine

ref.

Law

$0.040^{* * *} \quad 0.014$

Scientific

$0.028^{* * *} \quad 0.009$

Economics \& Statistics

$0.054^{* * *} \quad 0.011$

Social sciences

$0.034^{* * *} \quad 0.012$

Humanities

0.011

$0.027^{* * * *} \quad 0.009$

Interaction Crisis*Field of study

Law

$0.049^{* *} \quad 0.021$

Engineering \& Architecture

$0.063^{* * *} \quad 0.017$

Scientific

$0.047^{* * *} \quad 0.018$

Economics \& Statistics

$\begin{array}{ll}0.030 & 0.019\end{array}$

Social sciences

$0.039^{* *}$

0.017

Humanities

$0.050^{* * *}$

0.015

Parental education

Compulsory

Upper secondary

Tertiary

ref.

$0.024^{* * *} \quad 0.008$

$0.052^{* * *} \quad 0.010$

Parental social class

Service class

ref.

White collars

0.004

0.007

Self-employed

0.013

0.011

Working class

$0.023^{* * *}$

0.009

High school track

Academic

Technical

ref.

Vocational

$\begin{array}{ll}0.124^{* * * *} & 0.009 \\ 0.150^{* * * *} & 0.009\end{array}$

Final mark lower secondary school

Sufficient

Good

Very good

ref.

$-0.029^{*}$

$-0.056^{* * * *}$

0.014

$-0.066^{* * *}$

0.014

Excellent

ref.

$-0.046^{* * * *} \quad 0.009$

60-69

0.010

80-89

$-0.071^{* * *}$

0.010

Geographical area

North-west

ref.

North-east

$-0.027$

$0.058^{* * *}$

0.007

Centre

$0.165^{* * *}$

0.008

South

0.017 
Failure (yes)

$\begin{array}{ll}0.022 & 0.019\end{array}$

Remedial exams (yes)

$0.021^{* * *} \quad 0.007$

Sex (female)

$-0.009 \quad 0.006$

Age (more than 23 years)

$0.040^{* *} \quad 0.017$

Unemployment rate

$-0.018^{* * * *} \quad 0.002$

Constant

$0.174^{\text {**** }}$

0.022

$\operatorname{Pr}$ (enrollment)

Coeff.

Std. Err.

Crisis (yes)

$0.371^{*}$

0.026

Parental education

Compulsory

Upper secondary

ref.

Tertiary

$0.315^{* * *}$

0.024

$0.658^{* * *}$

0.039

Parental social class

Service class

White collars

Self-employed

Working class

ref.

$-0.060^{*} \quad 0.034$

$-0.223^{* * * *} \quad 0.039$

$-0.261^{* * *} \quad 0.033$

High school track

Academic

ref.

Technical

$-1.183^{* * *}$

0.027

Vocational

$-1.599^{* * *}$

0.026

Final mark lower secondary school

Sufficient

ref.

Good

$0.204^{* *}$

0.029

Very good

$0.334^{* * *}$

0.032

Excellent

$0.384^{* * *}$

0.035

Final mark upper secondary school

60-69

70-79

80-89

90-100

Geographical area

North-west

North-east

Centre

South

Islands

Failure (yes)

Remedial exams (yes)

Sex (female)

Age (more than 23 years)

Unemployment rate

Courses available ref.

$0.351^{* * *} \quad 0.026$

$0.670^{* * * *} \quad 0.031$

$1.040^{* * *} \quad 0.038$

ref.

$-0.113^{* * * *} \quad 0.028$

$0.122^{* * *} \quad 0.032$

$0.770^{* * *} \quad 0.063$

$0.848^{* * *} \quad 0.076$

$0.024 \quad 0.041$

$\begin{array}{ll}-0.008 & 0.024\end{array}$

$0.006 \quad 0.022$

$-0.394^{* * * *} \quad 0.036$

$-0.122^{* * *} \quad 0.009$

$0.001^{* * * *} \quad 0.000$ 
Rho

0.004

0.006

Sigma

0.315

0.003

Lambda

0.001

0.002

N. Non-selected

21,684

N. Selected

26,775

N. Total

48,459

Source: SPHG 2011 and 2015. Robust standard errors in parentheses. $* \mathrm{p}<0.1, * * \mathrm{p}<0.05, * * * \mathrm{p}<0.01$. 